\title{
Chemistry Teachers' Misconceptions Concerning Concept of Chemical Reaction Rate
}

\author{
Ali Kolomuç ${ }^{1}$ and Seher Tekin ${ }^{2, *}$ \\ ${ }^{1}$ Faculty of Education, Artvin Çoruh University, Artvin, Turkey \\ ${ }^{2}$ Faculty of Education, Amasya University, Amasya, Turkey
}

Received: 21 April 2011 - Revised: 15 June 2011 - Accepted: 01 July 2011

\begin{abstract}
Teachers play a great role in how students understand and learn the concepts taught in class. Studies show that teachers reflect their already-existing conceptual constructs and their problem-solving processes on students. This is also true of the misconceptions reflected in chemistry classes, especially when abstract concepts are being taught. The purpose of this study is to see the degree of understanding of chemistry teachers concerning the chemical reaction rate concept. A case study research method was used in the study whose sample consisted of 70 chemistry teachers from forty different cities in Turkey. The data were collected through a chemical reaction rate comprehension test comprising five open-ended questions. The results have indicated that teachers have some misconceptions concerning chemical reaction rate.
\end{abstract}

Keywords: Chemical Reaction Rate, Enthalpy, Reaction Mechanism, Misconception.

\section{Introduction}

Chemistry is the science of matter and the changes it undergoes. It also attempts to explain chemical phenomena of everyday life. The objectives of chemistry education in schools cover the fundamental concepts of chemistry that students should comprehend and the chemical processes that lie behind everyday phenomena. It is suggested that school education should enable students to understand their life (MNE, 2008). From this point of view, more comprehensive studies should be done regarding chemistry education looking for ways of making it easier for students to grasp concepts of chemistry. Over the last years, there have been studies focusing on the difficulties that student have learning and understanding concepts of chemistry. They indicate that students have a lot of misconceptions in field of chemistry (Osborne \& Cosgrove, 1983; Abraham, Grzybowski, Renner, \& Marek, 1992; Staver \& Lumpe, 1995; Ayas, Özmen \& Coştu, 2002; Coştu, 2007; Özmen, 2007). Over the recent years in science education specifically, chemistry education, there has been a prevailing learning theory; namely, constructivism. Students are not passive learners; on the contrary, they actively construct their knowledge on their mind (Fensham, 1992; Matthews, 2002; Duit, 2009). The constructivist learning theory argues that individuals generate knowledge and meaning by interacting with the environment. It is against passive learners (Duit \& Treagust, 1995; Brooks \& Brooks, 1999; Vermette, Foote, Bird, Mesibov, HarrisEwing \& Battaglia, 2001). 
Teachers offer students a variety of learning opportunities so that their students can construct knowledge properly during the learning process. They help the students construct their knowledge actively by encouraging those to participate in various learning activities or making use of different teaching materials. Problem-solving processes and explanations teachers used set an example of learning and presenting knowledge for students. In learning process students can construct knowledge correctly when their teachers help them. Otherwise, these may lead to misconceptions as chemistry classes include such processes as problemsolving, explaining or relating concepts. Teachers' lack of content knowledge causes the unawareness of students' misconceptions, alternative conceptions and learning difficulties Students' conceptions which are different from those generally accepted by the scientific community have been called misconceptions, preconceptions, alternative frameworks or alternative conceptions (Osborne \& Cosgrove, 1983; Bar \& Travis, 1991; Pardhan \& Bano, 2001; Halim \& Meerah, 2002; Özmen, 2007; Taber \& Tan, 2011). In recent years, misconceptions have a significant place in the studies related to chemistry teaching and learning. Many researchers have investigated degree of understanding and misconceptions about diverse chemistry concepts: acid and bases (e.g. Lin \& Chiu, 2007; Ross \& Munby, 1991; Schmidt, 1995), mole concept (e.g. Staver \& Lumpe, 1995), chemical equilibrium (e.g. Hackling \& Garnett, 1985; Yarroch, 1985; Gussarsky \& Gorodetsky, 1988; Camacho \& Good, 1989; Hines, 1990; Pardo \& Solaz-Patolez, 1995; Voska \& Heikkinen, 2000), solutions (e.g. Abraham, Williamson \& Westbrook, 1994; Ebenezer \& Ericson, 1996; Çalık, Ayas \& Roll, 2007), electrochemistry (e.g. Garnett, 1992), the structure of matter (e.g. Gabel, Samuel \& Hunn, 1987; Haidar \& Abraham, 1991), and chemical changes (e.g. Hesse \& Anderson, 1992).

In literature, there have also been many studies concerning chemical reaction rate (Çakmakçı, 2005; Çakmakçı, Leach \& Donnely, 2006; Taştan Kırık, Yalçınkaya \& Boz, 2010; Çakmakçı, Donnely \& Leach, 2005; Taştan Kırık \& Boz, 2010; Nakipoğlu, Benlikaya \& Kalın, 2002; Akkaya, 2003; Balc1, 2006; Bozkoyun, 2004; Van Driel, 2002; Tezcan \& Y1lmaz, 2003). There are two main idea dominated with those: one is to find the alternative conceptions of students (Çakmakçı, 2005; Çakmakçı, Leach \& Donnely, 2006; Nakipoğlu, Benlikaya \& Kalın, 2002), and two is to overcome identified alternative conceptions (Akkaya, 2003; Balc1, 2006; Bozkoyun, 2004; Van Driel, 2002; Tezcan \& Y1lmaz, 2003; Özmen, Demircioğlu \& Demircioğlu, 2009). In order to overcome misconceptions and replace them with the scientific ones, viz., conceptual change, a variety of methods have been used: laboratory activities (e.g. Akkaya, 2003; Özmen, Demircioğlu \& Demircioğlu, 2009), analogy-assissted change texts (e.g. Bozkoyun, 2004), group discussions (e.g. Bilgin, 2006), use of basic material (e.g.Van Driel, 2002), use of package software for computer-assisted teaching (e.g. Tezcan \& Yılmaz, 2003). Taştan Kırık, Yalçınkaya \& Boz (2010) investigated prospective chemistry teachers' misconceptions. They revealed that students had some misconceptions. This paper is intended to fill a gap in literature as few studies have been observed about chemistry teachers' misconceptions of chemical reaction rate.

The unit on "Chemical Reaction Rate" covers lots of fundamental chemistry concepts. The topics in the unit are the rate of reaction, activation energy, factors affecting the rate of reaction, collision theory, catalysts, enthalpy, and reaction mechanism, just a few to mention. These concepts are of utmost importance in order to understand the relations between chemical change and energy, the types of chemical reactions, and the chemical change processes. It is important for students of chemistry to understand chemical phenomena of everyday life and explain them from a chemical point of view as they happen. Çakmakçı, Donnelly J. \& Leach (2005) observed that high school or university students had various misconceptions of chemical reaction rate. Taştan Kırık and his collegueus (2010) detected 
prospective chemistry teachers' misconceptions. It is very likely that these misconceptions can be passed onto students. It is a known fact that misconceptions resist to change. Taken a look into the reasons for these misconceptions, some of them are known to result from teachers (Kwen, 2005; Taber \& Tan, 2011). In this respect, studies will be important if they include these misconceptions of working teachers because the misconceptions can possibly be reflected onto students. This paper also aims to identify misconceptions that teachers may have of chemical reaction rate.

\section{Methodology}

A case study research method was used in the study since it is appropriate for in-depth particular research. It is also effective to attain a desired goal in a short time (Çepni, 2003).

\section{Sample}

The sample consisted of 70 volunteer teachers with a work experience of 15-25 years. The research implemented on the In-service Education Centers of the Ministry of Education in Çanakkale, Erzurum, Yalova, and Muğla/Turkey. In these centers, in-service education courses were organized for chemistry teachers to introduce New Secondary School Chemistry Programs at different dates. They attended the in-service courses from 40 different cities in Turkey. One of the researchers carried out Chemical Reactions Rate Comprehension Test (CRRCT) to the sample while they were attending this course program.

\section{Instrumentation and Analysis}

Chemical Reactions Rate Comprehension Test (CRRCT): The data were collected through CRRCT which was developed by Çakmakçı (2005). The test was prepared to determine the degree of understanding the nine sub-concepts in the topic. The questions were asked to receive answers suitable for the open-ended question in the test. The test of concepts on the reaction rate of the teachers consisted of 9 questions which aggregated 19 with its substages. In this study, only five questions from CRRCT were used to determine teachers' misconceptions about reaction rate concept (Appendix 1). The questions in CRRCT and the concepts measured through the questions are given Table 1 .

The answers in the achievement test of concepts were broken down into the following comprehension categories (Table 2): Full Comprehension (FC), Partial Comprehension (PC), Partial Comprehension with a Specific Alternative Concept (PC-ASAC), Alternative Concepts (AC), and Lack of Comprehension (LC) (Abraham et al., 1992; Ayas, Özmen \& Coştu, 2002). The terms of alternative conceptions and misconceptions are the same meaning that can be used to refer to students'conceptions that are different from scientifically accepted ones (Özmen, 2007; Taber \& Tan, 2011). 
Table 1. The questions in the CRRCT and the concepts investigated.

\begin{tabular}{|c|c|}
\hline Question Headings & Concepts Investigated \\
\hline Q 1.a.Define the 'Rate of Reaction' concept. & Defining the 'Rate of Reaction'. \\
\hline $\begin{array}{l}\text { 1.b. Explain the change in the rate of reaction } \\
\text { from start to finish. }\end{array}$ & $\begin{array}{l}\text { Explaining how the rate of reaction } \\
\text { changes from start to finish. }\end{array}$ \\
\hline $\begin{array}{l}\text { Q 2. Investigating the rate of reaction-time } \\
\text { graph. }\end{array}$ & $\begin{array}{l}\text { Explaining the rate of reaction-time } \\
\text { graphs. }\end{array}$ \\
\hline $\begin{array}{l}\text { 2.a. What should the rate of reaction-time } \\
\text { graph look like? }\end{array}$ & $\begin{array}{l}\text { Explaining the relationship between } \\
\text { the rate of reaction and time. }\end{array}$ \\
\hline 2.b. Explain the rate of reaction-time graph. & $\begin{array}{l}\text { Explaining the rate of reaction-time } \\
\text { graph. }\end{array}$ \\
\hline Q 3. Investigating the reaction mechanism. & $\begin{array}{l}\text { Writing down the rate equation for } \\
\text { reactions on a mechanism. }\end{array}$ \\
\hline $\begin{array}{l}\text { 3.a. As of the graph in the test of concepts; } \\
\text { How many stages do you think the reaction } \\
\text { consists of? Explain the stages if the reaction is } \\
\text { on a mechanism. }\end{array}$ & $\begin{array}{l}\text { Explaining how the rate is determined } \\
\text { in reactions on a mechanism. }\end{array}$ \\
\hline $\begin{array}{l}\text { 3.b. If you think that the reaction consists of } \\
\text { more than one stage, explain which stage is } \\
\text { faster and which stage determines the rate of } \\
\text { reaction. }\end{array}$ & $\begin{array}{l}\text { Explaining how the rate is written } \\
\text { down in reactions on a mechanism. }\end{array}$ \\
\hline $\begin{array}{l}\text { Q 4. Investigating the rate of reaction - } \\
\text { Enthalpy relationship. }\end{array}$ & $\begin{array}{l}\text { The relationship between enthalpy and } \\
\text { the rate of reaction. }\end{array}$ \\
\hline $\begin{array}{l}\text { Q 5.a. Explain the concept 'Activation Energy'. } \\
\text { 5.b. Explain the relationship between } \\
\text { activation energy and the rate of reaction. }\end{array}$ & $\begin{array}{l}\text { Explaining the activation energy. } \\
\text { Explaining the relationship between } \\
\text { the activation energy and the rate of } \\
\text { reaction }\end{array}$ \\
\hline
\end{tabular}

Table 2. Categories of comprehension used to analyse the answers in the comprehension test

\begin{tabular}{ll}
\hline Degrees of Comprehension & Rating Criteria \\
\hline Full Comprehension(FC) & Answers covering all aspects of correct answer \\
Partial Comprehension(PC) & $\begin{array}{l}\text { Answers covering one aspect, but not all aspects of } \\
\text { correct answer }\end{array}$ \\
$\begin{array}{l}\text { Partial Comprehension with a Specific } \\
\text { Alternative Concept (PC-ASAC) }\end{array}$ & $\begin{array}{l}\text { an alternative concept at the same time } \\
\text { Scientifically incorrect answers }\end{array}$ \\
Alternative Concepts(AC) & $\begin{array}{l}\text { Answers left blank, Question repetition, Irrelevant or } \\
\text { unclear answers, I don't know, I don't understand. }\end{array}$ \\
\hline
\end{tabular}


The reason why these questions were selected was to determine teachers' misconceptions about reaction rate concept, and to find out more about their command of the concepts in the unit. The questions were asked to receive answers suitable for the open-ended question in the test.

\section{Findings}

In Table 3 below are the answers given by the teachers to the test of concepts and the percentages there of.

Table 3. Answers given by the teachers to the test of concepts and the percentages

\begin{tabular}{ccccccccccc}
\hline Questions & \multicolumn{2}{c}{ FC } & \multicolumn{2}{c}{ PC } & \multicolumn{2}{c}{ (PC-ASAC) } & \multicolumn{2}{c}{ AC } & \multicolumn{2}{c}{ LC } \\
\hline & $f$ & $\%$ & $f$ & $\%$ & $f$ & $\%$ & $f$ & $\%$ & $f$ & $\%$ \\
\hline $1-\mathrm{a}$ & 50 & 72 & - & - & 11 & 14 & 11 & 14 & - & - \\
$1-\mathrm{b}$ & 51 & 73 & - & - & 14 & 20 & 5 & 7 & - & - \\
$2-\mathrm{a}$ & 39 & 55 & 9 & 13 & 9 & 13 & 13 & 19 & -- & -- \\
$2-\mathrm{b}$ & 40 & 57 & -- & -- & 17 & 24 & -- & -- & 13 & 19 \\
$3-\mathrm{a}$ & 40 & 57 & -- & -- & 14 & 20 & -- & -- & 16 & 23 \\
$3-\mathrm{b}$ & 29 & 41 & -- & -- & 15 & 21 & - & - & 26 & 32 \\
4 & 24 & 34 & - & - & 21 & 30 & 9 & 13 & 16 & 23 \\
$5-\mathrm{a}$ & 60 & 86 & 5 & 7 & - & - & - & - & 5 & 7 \\
$5-\mathrm{b}$ & 60 & 86 & 4 & 5 & - & - & - & - & 6 & 9 \\
\hline
\end{tabular}

Below are the details of the answers given by the teachers to the questions in CRRCT.

Question 1: $72 \%$ of all the teachers answered question 1.a in the FC category correctly (Table 3 ). The rate of reaction was defined as "It is the amount of reactant that takes part in a chemical reaction in a given time" or "It is the amount of reactant formed in a given time."

$14 \%$ of all the answers were in the PC-ASAC category. The answers given were as below: "In single-step reactions, the rate of reaction is equal to the multiplication of the reactants that take part in the chemical reaction", "The rate of reaction can be expressed by A, B, C substances.", "It shows how long the reaction took place." and "In multi-step reactions, the rate of reaction is the slowest step.", "The reactants in the reaction to complete the reaction can be expressed as the rate of reaction."

$14 \%$ of all the answers were in the AC category. Below were the misconceptions provided by the teachers: "It is the collision of A and B in a given time.", "The rate of reaction is the transformation of mass in a given time." and "The rate can change depending on the type due to the fact that the reactant is in dust particles and the surface area is large?"

$73 \%$ of the teachers answered question 1.b correctly. The following answer was in the FC category: "The rate of reaction is faster at the beginning and then slows down as the particles to be collide in the reaction decrease in quantities."

$20 \%$ of the teachers answered the questions in the PC-ASAC category. There were statements such as "The rate of reaction remains stable from start to finish.", "Some chemical 
reactions proceed at an increasing rate, and some at a decreasing rate.", "The rate of reaction slows down over time, but the average is used in calculations." and "The rate may increase or decrease. However, it remains stable at the end." $7 \%$ of all the answers were in the AC category: The statements below can be regarded as alternative concepts: "The rate of reaction is/isn't affected by the concentration of reactant that take part in the reaction." and "The rate of reaction is explained trough the change in pressure, conductivity and colour."

Question 2: The answers and the percentages to the question 2.a investigating the change of rate of reaction-time graph can be seen in Table 3. Below in Figure 1 are the graphs drawn and the explanations made by the teachers. The Turkish terms in the graph read as Reaksiyon $\mathrm{H}_{1 \mathrm{z}}=\mathrm{The}$ Rate of Reaction, Zaman=Time.

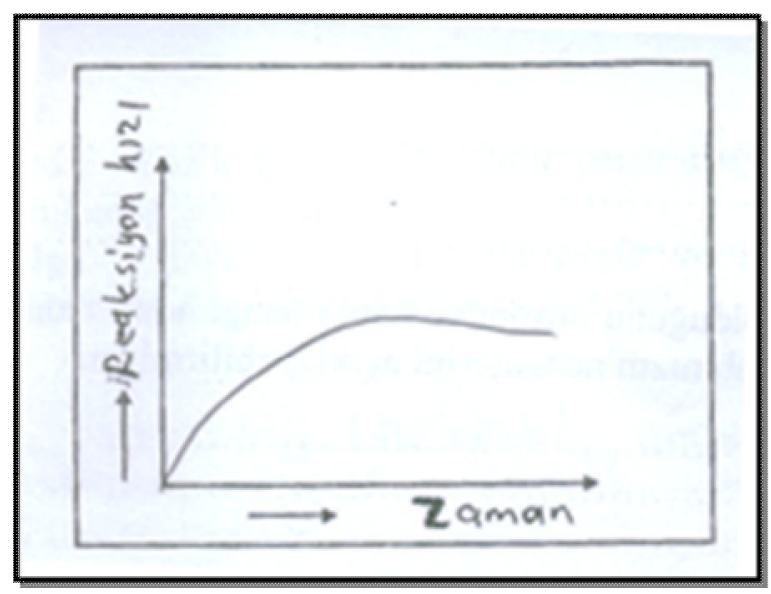

(a)

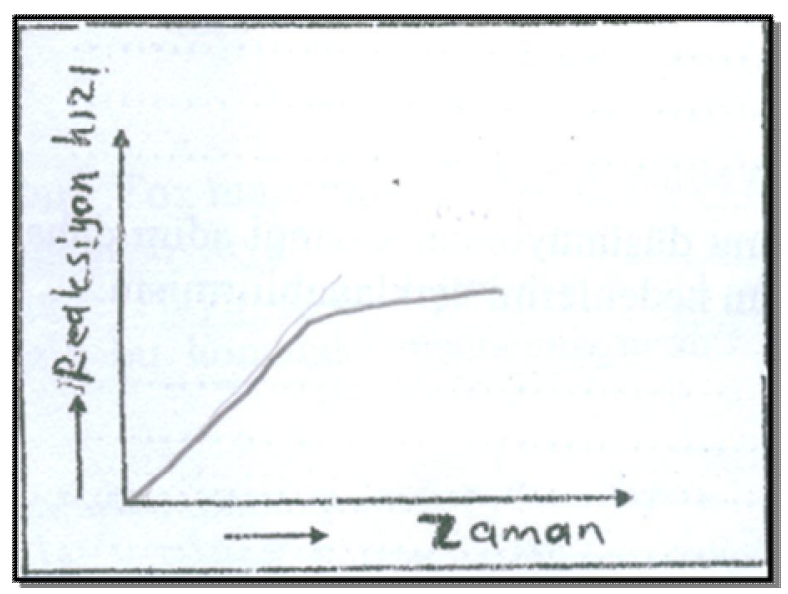

(c)

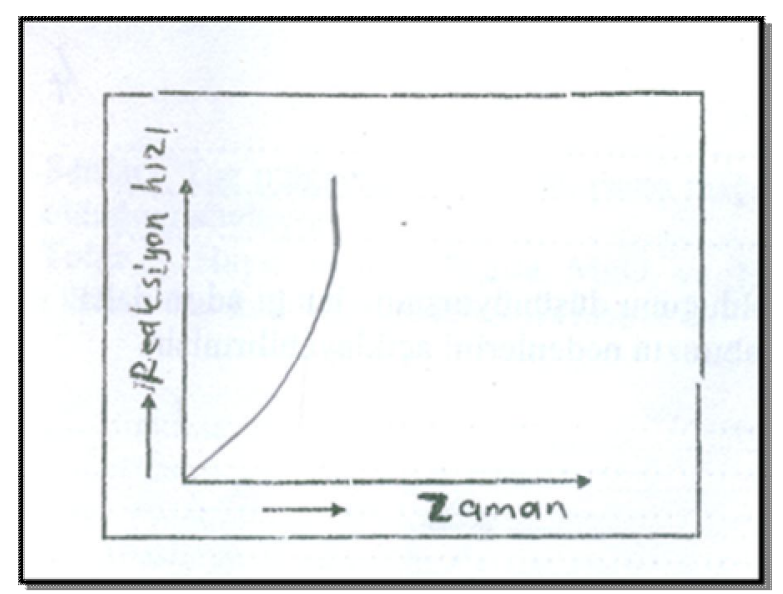

(b)

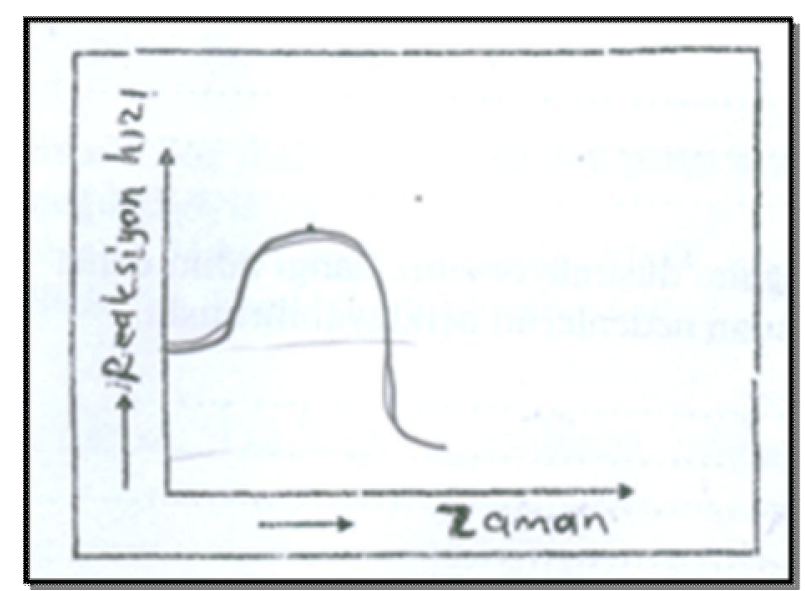

(d)

Figure 1: The reaction rate-time graphs drawn by the teachers

$55 \%$ of the graphs drawn by the teachers were in the FC category. $13 \%$ of them were in the PC category. $13 \%$ of them were in the PC-ASAC category. $19 \%$ of them were in the AC category. As of the explanations of the graphs, $57 \%$ were in the FC category. The statements were like the following: "as drawn by Pelin, the rate of reaction won't be stable". "When taken in millimeters, the rate of reaction appears to be slowing down." "Since the amount of the reactant is a lot at the beginning, the rate of reaction is fast. As the amount gets lesser, the 
rate of reaction gets stable", "The rate of reaction depends on whether it is endothermic or exothermic or not", "The rate decreases as the rate of reaction decreases in time", "Because the concentration of A decreases, the rate of reaction increases", "There is no rate of reaction at the beginning. It increases in time and decreases at the end", "As soon as the reaction begins, the rate of reaction reaches the maximum level, and then slows down" and "The rate of reaction increases for a time and then slows down".

$24 \%$ of the answers were in the PC-ASAC category. The statements were like the following: "the rate of reaction didn't remain stable because there were no substances affecting the reaction", "The substances lose their characteristics since the concentrations decrease over time", "The reaction is realised and the rate of reaction gets faster and faster" and "The rate of reaction increases as the concentration of a decreases".

Question 3: The answers and the percentages to the question 3.a investigating the reaction mechanism can be seen in Table 3. In those in the FC category, the reaction consists of two steps and the mechanism was as follows:

$$
\text { X--------> j (Fast) J -------> Q (Slow) }
$$

$57 \%$ of all the answers were in the FC category. $20 \%$ of the answers were in the PCASAC category. The statements were like the following: "The reaction is a single-step one.", "The rate of reaction may not be stable.", "The reaction happened in a single step and $\mathrm{J}$ is an activated complex." $23 \%$ of the answers were in the LC category. There were such statements as "I am sorry, but I am not sure." and "The reaction consists of three steps."

The answers and the percentages to the question 3.b investigating the reaction mechanism can be seen in Table 3. In those in the FC category, the reaction consists of two steps and the mechanism was as follows:

$$
\text { X-------> j (Fast) J -------> Q (Slow) }
$$

"The amount of $\mathrm{J}$ was formed and used. $\mathrm{J}$ was a bye-product. The second step was slower. We can see that the first step was faster by looking at the number of particles exceeding the complex that got active." $41 \%$ of the answers were in the FC category. $21 \%$ of the answers were in the PC-ASAC category. The statements were as follows: "There is no information about the activation energies. Therefore, we can't determine the slow step.", "The reaction occurs two steps and the rate of reaction is determined by the first reaction, i.e. the slow one.", "The reaction is a single-step one". $38 \%$ of the answers were in the AC category. There were statements like "It can not be found due to insufficient information.","no answer".

Question 4: The answers and the percentages to the question 4 investigating the relationship between the rate of and enthalpy in chemical reactions can be seen in Table 3. 34\% of the answers were in the FC category. The statements below can be exemplary: "The rate of reaction can not be compared to the information. The activation energy determines the rate of reaction. As the activation energy is unknown, there is no knowing which one is faster."

$30 \%$ of the answers were in the PC-ASAC category. There was such a statement as "The first reaction (exothermic reaction) is faster, I agree with Serap - one of the teachers". $13 \%$ of the answers were in the AC category. The statements were as follows: "Exothermic reactions are faster than endothermic reactions.", "The rates of exothermic and endothermic reactions are equal as the temperatures are the same.", "Exothermic reactions are faster because there is a need for heat so that reactions can take place.", "Exothermal reactions are faster since their activation energies are lower." and "The first reaction is faster because the 
temperature gets high over time". $23 \%$ of the answers were in the LC category. The statements were as follows: "Even if the temperature is the same, $\Delta \mathrm{H}_{1}$ and $\Delta \mathrm{H}_{2}$, the sum of the inner energies of the reactants and the products can be different." and "If the temperatures are equal, the rates of the reactions are the same."

Question 5: The answers and the percentages to the question 5.a explaining the concept of activation energy can be seen in Table $3.86 \%$ of the answers were in the FC category. There were statements such as "activation energy is the minimum amount of energy that the particles undergoing a reaction must have in order to form a reaction when they collide". $7 \%$ of the answers were in the PC category. The statements were like "It is the energy of particles colliding.", "It is the required amount of energy for the particles in a reaction to collide in the right direction." and "Temperature enables the rate of reaction to increase by lowering the activation energy". 7\% of the answers were in the LC category. There were statements like "I haven't got an answer."

The answers and the percentages to the question 5.b explaining which reaction was faster by activation energy can be seen in Table 3. $86 \%$ of the answers were in the FC category. There were such statements as "The lesser the activation energy, the higher the reaction takes place. It takes shorter to get over the obstacle of energy. Therefore, the activation energy of the first reaction is lower then the second one and the first reaction is faster". 5\% of the answers were in the PC category. There were such statements as "Reactions between ions are usually quite fast." or "Even if it is given the value of Ea, the rate of reaction depends on whether the particles are single-atom or multi-atom.", "Nothing is said for sure." and "In reactions with high activation energies, the probability that molecules may collide gets less". 9\% of the answers were in the LC category. There were statements like "I haven't got an answer."

\section{Results and Discussion}

The identified misconceptions by the CRRCT are presented in Table 4 . When Table 4 is examined, it can be seen in many misconceptions that teachers have.

In Question 1, the comprehension levels of chemistry teachers concerning the concept of chemical reaction rate were investigated. Even though most of the teachers explained the concept of chemical reaction rate correctly, some misconceptions were observed (Table 4). There were such misconceptions that the teachers have about the rate of reaction as "The period of time in which reactant undergoes a reaction or products are formed in a reaction", "The period of time from when at least two reactants undergo a reaction to when a product is formed", "The period of time needed for new elements to undergo a reaction", "That reactants in a reaction bring the reaction to an end" or "The amount of matter that undergoes a change in a reaction".

These misconceptions resemble those observed in the studies carried out by Nakipoğlu, Benlikaya \& Kalın (2002), Çakmakçı (2005), Kolomuç (2009), Çalık, Kolomuç \& Karagölge (2010), and Çakmakç1 (2010). They may result from the fact that the teachers confuse the rate of reaction with the time in which a reaction is completed or they may not distinguish between them. This can be due to the fact that the teachers were preparing students for the University Entrance Exam by making use of multiple-choice questions instead of open-ended ones. 
Tablo 4. Determined misconceptions about the unit of reaction rate in this study

\begin{tabular}{ll}
\hline Concept & Determined misconceptions about concepts \\
\hline Defining and & 1. In single-step reactions, the rate of reaction is equal to the \\
explaining of the Rate & multiplication of the reactants that take part in the chemical reaction \\
of Reaction & 2. It shows how long the reaction took place \\
3. In multi-step reactions, the rate of reaction is the slowest step. & 4. It is the collision of A and B in a given time \\
5. The rate of reaction is the transformation of mass in a given time. & 1. The rate of reaction remains stable from start to finish. \\
\hline Explaining how the rate & 2. Some chemical reactions proceed at an increasing rate, and some at \\
of reaction changes & $\begin{array}{l}\text { a decreasing rate. } \\
\text { from start to finish }\end{array}$ \\
3. The rate may increase or decrease. However, it remains stable at \\
the end. \\
4. The rate of reaction is/isn't affected by the concentration of \\
reactant that take part in the reaction. \\
5. The rate of reaction is explained trough the change in pressure, \\
conductivity and colour.
\end{tabular}

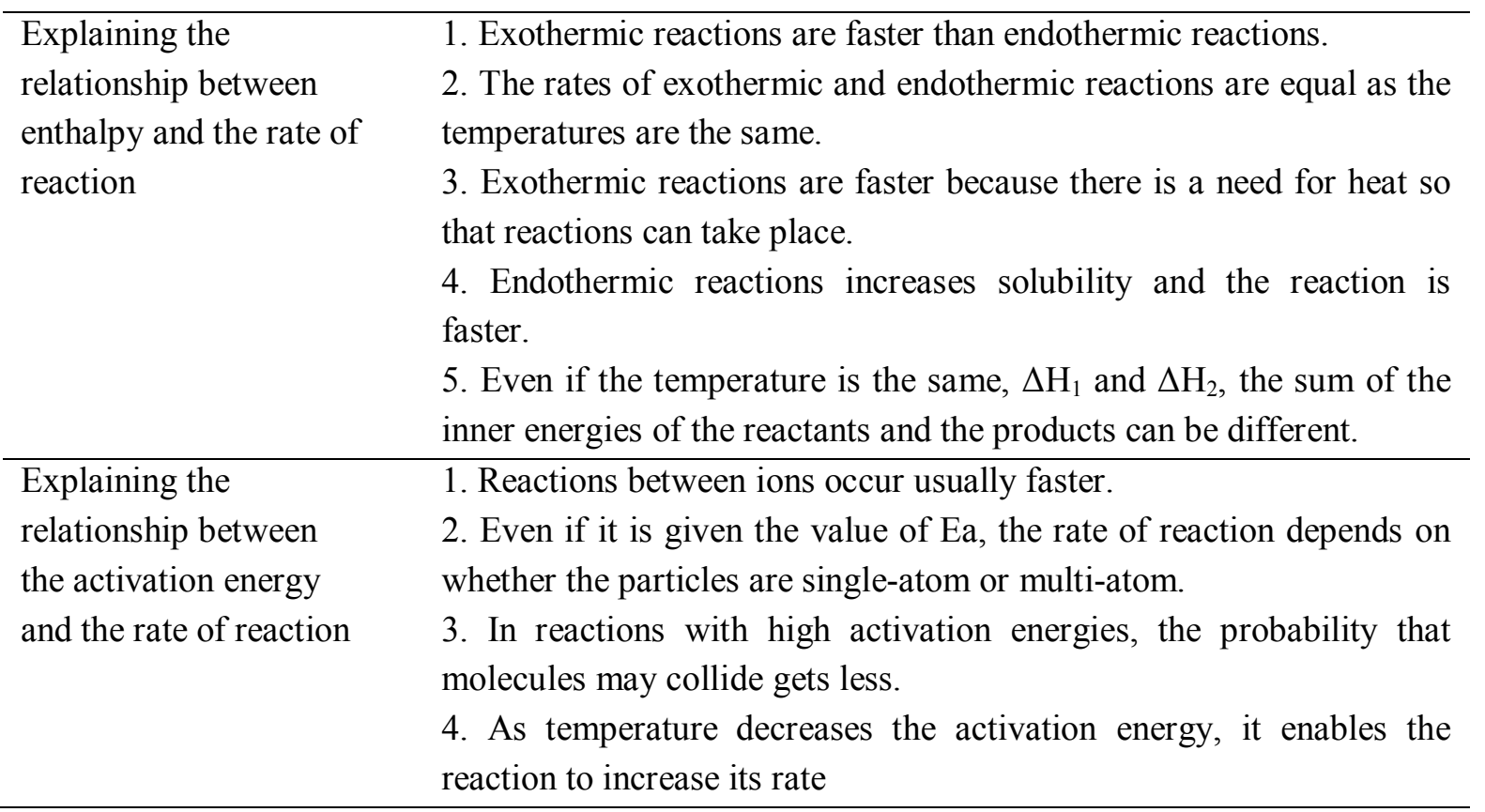


In Question 2, the teachers were required to draw and explain the rate of reaction-time graph. The graphs show that most of the teachers couldn't draw the rate of reaction-time graph by reactants and products. Some of the teachers drew the graph by assuming the rate of reaction to be fixed and stated that the rate of reaction could change with only temperature and a catalyst. Some of the explanations made indicated misconceptions: "the rate of reaction didn't remain stable because there were no substances affecting the reaction", "The reaction is realised and the rate of reaction gets faster and faster" These misconceptions observed similarly in the studies carried out by Çakmakç1 2005; Kolomuç 2009; Çalık, Kolomuç \& Karagölge 2010.

In Question 3, determining the reaction mechanism was investigated. The percentage of the correct answers to this question is relatively very low. This may have stemmed from the fact that the teachers had an insufficient command of comprehending graphs (Johnstone 1991; Kozma 2003; Coştu 2007; Kolomuç 2009). There were such statements as "the reaction consists of 3 steps", "L is a catalyst", "the first step determines the rate of reaction", and "the reaction doesn't consist of a mechanism. There must be products, reactants and a catalyst". These statements showed that teachers had difficulties in understanding the reaction mechanism and determining the reaction mechanism by analysing a time-concentration graph.

In Question 4, comparisons of the rates of endothermic and exothermic reaction were investigated. Such alternative concepts were detected (Table 4): "Exothermic reactions are faster", "Endothermic reactions increase solubility, and the reaction is faster", "In exothermic reactions, heat from outside is needed and the reaction is faster", "The rate of reaction is the same in endothermic and exothermic reactions", and "Even if the temperature of the reaction is the same in endothermic and exothermic reactions, $\Delta \mathrm{H}_{1}$ and $\Delta \mathrm{H}_{2}$, the sum of the inner energies of the reactants and the products can be different". This result coincides with Çakmakçı (2005), Kolomuç (2009), Çalık, Kolomuç \& Karagölge (2010). As a result, we can say that teachers had some difficulties in explaining the relationship between enthalpy and rate of reaction.

In Question 5, the concept of activation energy, and the relationship between the activation energy and the rate of reaction were investigated. Most of teachers explained the concept of activation energy correctly. However, there were some misconceptions such as "As temperature decreases the activation energy, it enables the reaction to increase its rate", "Activation energy is the energy required for the particles in the reaction to collide in the appropriate direction", and "It is the energy of particles colliding". The findings indicate that the teachers confuse the activation energy with the collision theory. With respect to the relationship between the activation energy and the rate of reaction, there was an alternative concept like "Reactions between ions occur usually faster."

The results showed that teachers have some misconceptions about reaction rate concept. The results clearly indicated that the basic concepts about reaction rate are hardly understood by some teachers that participated in this study, though all have taught chemistry in their classes for years. Some teachers have difficulty in explaining how the reaction rate changes from start to finish. In light of these results, it should be said that teachers should be supported with professional development. Therefore, in-service education activities should be designed so that these identified misconceptions can be removed. In this respect, they can be informed of the misconceptions and be encouraged to revise what they know.

The research conclusions showed that chemistry teachers and students have similar misconceptions about reaction rate. This is rather surprising, since we would expect that teachers' understanding would be better than students' understanding. One reason for this may be that teachers constructed on this topic inadequately or superficially in their mind. 
Therefore, as teachers may develop a simple understanding of the reaction rate meaning, then they can go on and use their mental model in everyday teaching practices. Research has shown that misconceptions among pupils are resistant to change, and that persist even with formal instruction. Misconceptions among teachers may be resistant to change, too. Kwen (2005) examined primary school teachers' misconceptions concerning some key biyology science concepts in the areas of plant and animal morphology, function and genetics. Some of teachers' misconceptions were similar to students' misconceptions. Pardhan \& Bano (2010) found similar difficulties on teachers' understanding of electrical current. They asked a question that "What are the possible reasons of this situation?" They had summarized some possible reasons: the way teachers were taught, textbooks, intuitive/direct observations of events from daily life, use of terms/words/metaphors in everyday language, lack of contextual hand-on and minds-on "doing science" experiences to link with abstractions to construct schemas and superficial as opposed to in-depth and breadth of subject matter knowledge. These reasons we can add into the central university entrance examination that teachers are tent to problem-solving activities to prepare their students for this exam in their classes.

The general conclusion was that teachers should be informed about what misconceptions are resistant to change and the most effective barrier for students to understand chemistry and science. This study has also helped these teachers realize what they already know on the reaction rate concept. Other studies can be designed to identify misconceptions about other chemical concepts.

\section{References}

Abraham, M.R., Grzybowski, E.B., Renner, J. \& Marek, E.A. (1992). Understandings and misunderstandings of eight graders of five chemistry concepts found in textbooks. Journal of Research in Science Teaching, 29(2), 105-120.

Abraham, M.R., Williamson, V.M. \& Westbrook, S.L. (1994). A cross-age study of the understanding of five chemistry concepts. Journal of Research in Science Teaching, 31(2), 147-165.

Akkaya, C.G. (2003). Comparison of teaching the relation rate course using the traditional and the experimental training methods on students success in lycee 2 classes. Unpublished Master Thesis, Marmara University, Turkey.

Ayas, A., Özmen, H. \& Coştu, B. (2002). The Determination of the secondary school students'understandings about evaporation concept. Dokuz Eylül University Journal of Buca Faculty of Education, 14, 74-84.

Balc1, C. (2006). Conceptual change text oriented instruction to facilitate conceptual change in rate of reaction concepts. Unpublished Master Thesis, METU, Turkey.

Bar, V. \& Travis, A. (1991). Children's views concerning phase changes. Journal of Research in Science Teaching, 28(4), 363-382.

Bilgin, İ. (2006). Promoting pre-service elementary students' understanding of chemical equilibrium through discussions in small groups. International Journal of Science and Mathematics Education, 4(3), 467-484.

Bozkoyun, Y. (2004). Facilitating conceptual change in learning rate of reaction concepts. Unpublished Master Thesis, METU, Ankara.

Brooks, J.G. \& Brooks, M.G. (1999). In Search of Understanding: The Case for Constructivist Classrooms. Association for Supervision and Curriculum Development, Alexandria. 
Camacho, M. \& Good, R. (1989). Problem solving and chemical equilibrium: successful vs. unsuccessful performance. Journal of Research in Science Teaching, 26(3), 251-272.

Coştu, B. (2007). Comparison of students' performance on algorithmic, conceptual and graphical chemistry gas problems. Journal of Science Education and Technology, 16(5), 379-386.

Çakmakçı, G. (2005). A cross-sectional study of the understanding of chemical kinetics among Turkish secondary and undergraduate student. Unpublished doctoral dissertation, The University of Leeds, UK.

Çakmakçı, G, Donnelly J. \& Leach, J. (2005). A cross-sectional study of the understanding of the relationships between concentration and reaction rate among Turkish secondary and undergraduate students. In: Boersma K, de Jong O, Eijkelhof H, Goedhart M (eds) Research and the quality of science education. Springer, Dordrecht, pp. 483-497.

Çakmakçı, G., Leach, J. \& Donnelly, J. (2006). Students' ideas about reaction rate and its relationship with concentration or pressure. International Journal of Science Education, 28(15), 1795-1815.

Çakmakçı, G. (2010). Identifying alternative conceptions of chemical kinetics among secondary school and undergraduate students in Turkey. Journal of Chemical Education, 87(4), 449-455.

Çalık, M., Ayas, A. \& Coll, R.K. (2007). Enhancing pre-service primaryteachers' conceptual understanding of solution chemistry with conceptual change text. International Journal of Science Mathematics Education, 5(1), 1-28.

Çalık, M., Kolomuç, A. \& Karagölge, Z. (2010). The effect of conceptual change pedagogy on students' conceptions of rate of reaction. Journal of Science Education and Technology, 19(5), 422-433.

Çepni, S. (2003). Araştırma ve Proje Çalışmalarına Giriş. Erol Ofset, Trabzon. (In Turkish)

Duit, R. \& Treagust, D.F. (1995). "Students' conceptions and constructivist Teaching approaches" in Improving Science Education. Edited by Barry J. Fraser \& Herbert J. Walberg, pp. 46-69. University of Chicago Press, Chicago.

Duit, R. (2009). STCSE - Bibliography: Students' and teachers' conceptions and science education. Kiel, Germany: IPN - Leibniz Institute for Science Education, http://www.ipn.uni-kiel.de/aktuell/stcse/stcse.html, retrieved date: 16.09.2010.

Ebenezer, J.V. \& Erickson, L.G. (1996). Chemistry students' conception of solubility: A phenomenograpy. Science Education, 80(2), 181-201.

Fensham, P.J. (1992). Science and Technology. In PW Jackson (Ed.), Handbook of research on curriculum, pp. 789-829, NewYork: Macmillan.

Gabel, D.L., Samuel, K.V. \& Hunn, D. (1987). Understanding the particulate nature of matter. Journal of Chemical Education, 64(8), 695-697.

Garnett, P.J. (1992). Conceptual difficulties experienced by senior high school students of electrochemistry. Electric circuits and oxidation reduction equations. Journal of Research in Science Teaching, 29(2), 121-142.

Gussarsky, E. \& Gorodetsky, M. (1988). On the chemical equilibrium concept: constrained word associations and conception. Journal of Research in Science Teaching, 25(5), 319333. 
Hackling, M.W. \& Garnett, P.J. (1985). Misconceptions of chemical equilibrium. International Journal of Science Education, 7(2), 205-214.

Haidar, H.A. \& Abraham, R.M. (1991). A comparison of applied and theoretical knowledge of concept based on the particulate nature of matter. Journal of Research in Science Teaching, 28(10), 919-938.

Halim, L. \& Meerah., S. (2002). Science trainee teachers' pedagogical content knowledge and its influence on physics teaching. Research in Science \& Technological Education, 20(2), 215-225.

Hesse, J.J. \& Anderson, C.W. (1992). Students' conceptions of chemical change. Journal of Research in Science Teaching, 29(3), 277-299.

Hines, C. (1990). Students' understanding of chemical equations in secondary school in Botswana. School Science Review, 72(258), 138-140.

Johnstone, A.H. (1991). Why is science difficult to learn? Things are seldom what they seem. Journal of Computer Assisted Learning, 7(2), 75-83.

Kolomuç, A. (2009). Animation aided instruction on "rate of chemical reactions" unit in grade 11 in regard to $5 E$ model. Unpublished Doctoral Dissertation. Atatürk University, Turkey.

Kozma, R.B. (2003). The material features of multiple representations and their cognitive and social affordances for science understanding. Learning and Instruction, 13(2), 205-226.

Kwen, B.H. (2005). Teachers' misconceptions of biological science concepts as revealed in science examination papers. AARE 2005 International Education Research Conference, http://www.aare.edu.au/05pap/boo05099.pdf., retrieved date: 26.11.2010.

Lin, J.W. \& Chiu, M.H. (2007). Exploring characteristics and diverse sources of students' mental models in acids and bases. International Journal of Science Education, 29(6), 771-803.

Matthews, M.R. (2002). Constructivism and science education: A further appraisal. Journal of Science Education and Technology, 11(2), 121-134.

MNE - Ministry of National Education- (2008). The Programme of Secondary School Chemistry ( $11^{\text {th }}$ grade), Turkey.

Nakipoğlu C., Benlikaya R. \& Kalın S. (2002). Usage of V-diagrams in eliciting pre-service chemistry teachers' misunderstanding of chemical kinetic. http://www.fedu.metu. edu.tr/ufbmek-5/b_kitabi/PDF/Kimya/Bildiri/t179d.pdf., retrieved date: 19.11.2010.

Osborne, R. \& Cosgrove, M. (1983). Students' conceptions of the changes of states of water. Journal of Research in Science Teaching, 20(9), 825-838.

Özmen, H. (2007). The effectiveness of conceptual change texts in remediating high school students' alternative conceptions concerning chemical equilibrium. Asia Pacific Education Review, 8(3), 413-425.

Özmen, H., Demircioğlu, H. \& Demircioğlu, G. (2009). The effects of conceptual change texts accompanied with animations on overcoming $11^{\text {th }}$ grade students'alternative conceptions of chemical bonding. Computers \& Education, 52(3), 681-695.

Pardhan, H. \& Bano, Y. (2001). Science teachers' alternate conceptions about direct-currents. International Journal of Science Education, 23(3), 301-318. 
Pardo, J.Q. \& Solaz-Patolez, J.J. (1995). Students' and teachers' misapplication of Le Chatelier's principle: implications for teaching of chemical equilibrium. Journal of Research in Science Teaching, 32(9), 939-957.

Ross, B. \& Munby, H. (1991). Concept mapping and misconceptions: a study of high school students' understandings of acids and bases. International Journal of Science Education, 13(1), 11-23.

Schmidt, H.J. (1995). Applying the concept of conjugation to the Bronsted theory of acidbase reactions by senior high school students from Germany. International Journal of Science Education, 17(6), 733-742.

Staver, J.R. \& Lumpe, A.T. (1995). Two investigations of students understanding of the mole concept and its use in problem solving. Journal of Research in Science Teaching, 32(2), 177-193.

Taber, K.S. \& Tan, K.C.D. (2011). The insidious nature of 'hard-core' alternative conceptions: implications for the constructivist research programme of patterns in high school students' and pre-service teachers' thinking about ionisation energy. International Journal of Science Education, 33(2), 259-297.

Taştan Kırık, Ö., Yalçınkaya, E. \& Boz, Y. (2010). Pre-service chemistry teachers' ideas about reaction mechanism. Journal of Turklsh Sclence Educatıon, 7(1), 47-60.

Taştan Kırık, Ö. \& Boz, Y. (2010). Effect of cooperative learning on students'understanding of reaction rate. XIV. Symposium of the International Organization for Science and Technology Education (IOSTE), Bled, Slovenia, 13-18 June. http://files.ecetera.si /IOSTE/155.pdf., retrieved date: 07.02.2011.

Tezcan, H. \& Yilmaz, U. (2003). The effect of conceptual computer animations and traditional instruction in teaching chemistry on student achievement. Pamukkale University Journal of Faculty Education, 14(2), 18-32.

Van Driel, J.H. (2002). Students' corpuscular conceptions in the context of chemical equilibrium and chemical kinetics. Chemistry Education Research \& Practice in Europe, 3(2), 201-213.

Vermette, P., Foote, C., Bird, C., Mesibov, D., Harris-Ewing, S. \& Battaglia, C. (2001). Understanding constructivism(s): a primer for parents and school board members. Education, 122(1), 87-93.

Voska, K.W. \& Heikkinen, H.W. (2000). Identification and analysis of student conceptions used to solve chemical equilibrium problems. Journal of Research in Science Teaching, $37(2), 160-176$.

Yarroch, W.L. (1985). Students' understanding of chemical equation balancing. Journal of Research in Science Teaching, 22(5), 449-459. 


\section{Appendix 1. CHEMICAL REACTION RATE COMPREHENSION TEST}

\section{Reaction Rate:}

Question 1. Consider a reaction where chemicals ' $A$ ' and ' $B$ ' react to form ' $C$ '

$$
\mathrm{A}+\mathrm{B} \rightarrow \mathrm{C}
$$

Halil, a student in the class, says: "The reaction rate is the rate of formation of ' $\mathrm{C}$ ' and it increasing during time"

His friend Sabri disagrees: "No, the rate of reaction shows the period of time that is required for a reaction to occur"

The students are having some problems! Answer question (a) and (b) to help the boys to understand!

a)Explain in your own words what you understand by the term "rate of reaction"

b) How does the rate of reaction change from the beginning until the end of the reaction? Please explain your answer as fully as you can!

\section{Reaction rate-time}

Question 2. Consider a reaction where two chemicals ' $A$ ' and ' $B$ ' react form ' $C$ '

$$
\mathrm{A}_{(\mathrm{aq})}+\mathrm{B}_{(\mathrm{aq})} \rightarrow \mathrm{C}_{(\mathrm{aq})}
$$

The teacher drew a graph showing how the concentration of A changes with time.

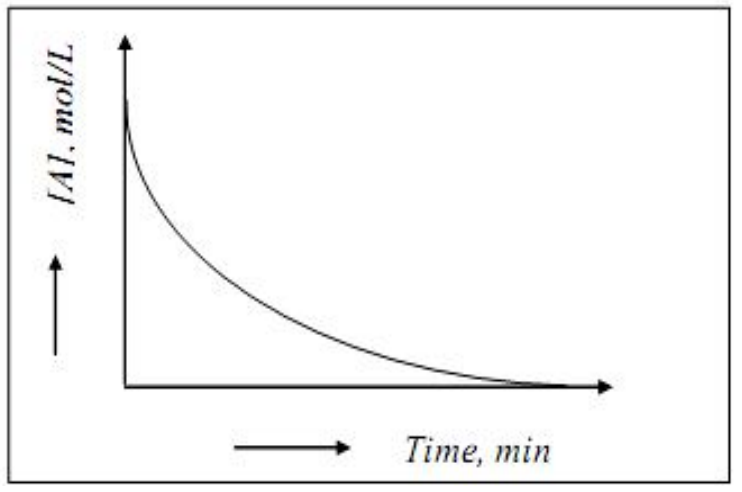

The teacher asks Pelin and yeliz to use the graph to draw a graph for the reaction rate against time. 

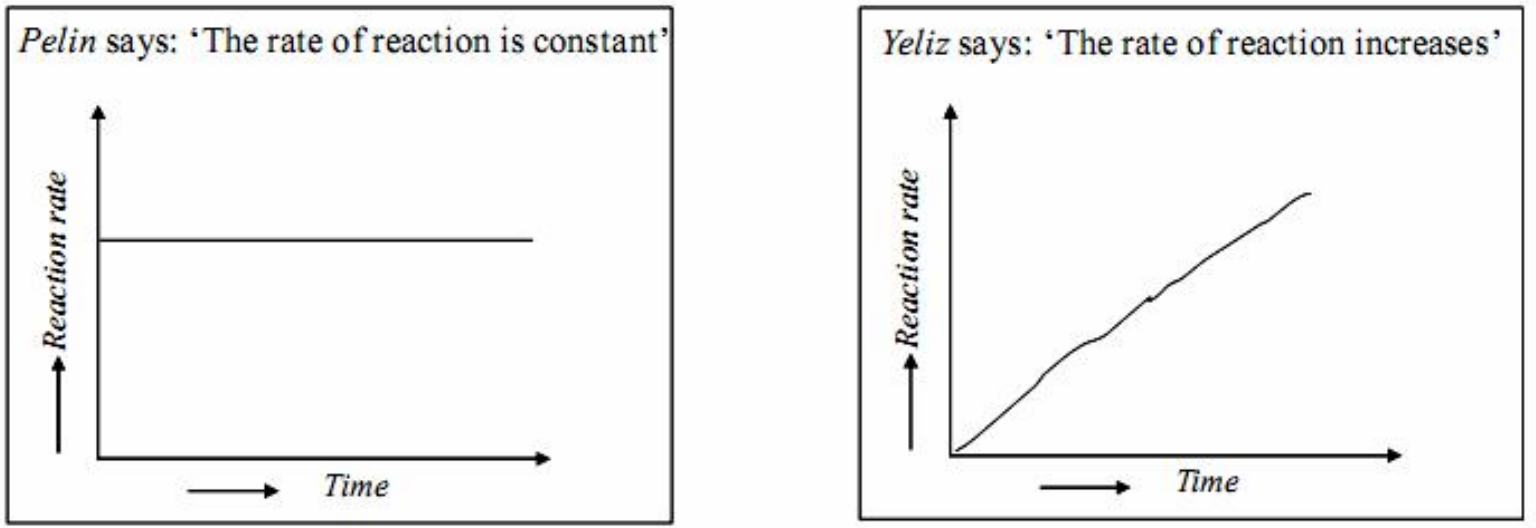

a) What is your opinion? Make a drawing to show the rate of reaction against time.

b) What would you say to convince the girl(s) that your answer is correct? Give as much detail as you can!

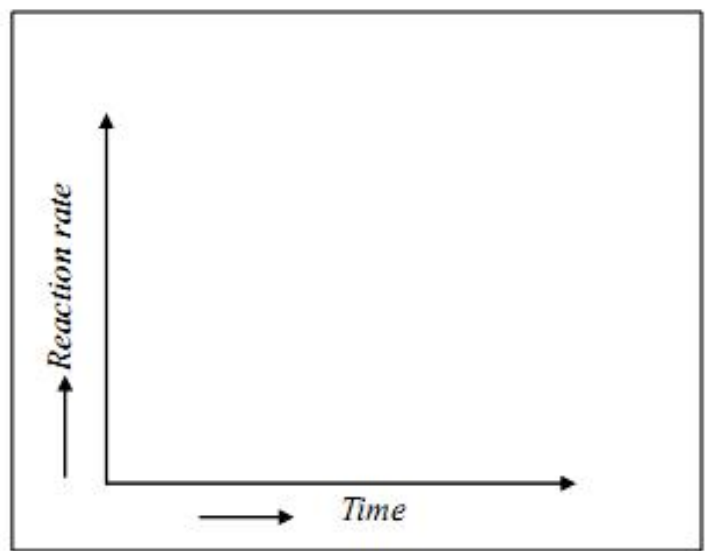

\section{Question 3. Reaction mechanisms:}

Some scientists did an experiment to discover the mechanism of the decomposition of element $\mathrm{X}$ to element Q: $\mathrm{X} \rightarrow \mathrm{Q}$

They measured the concentration of the substances involved in the reaction and created the graph below.

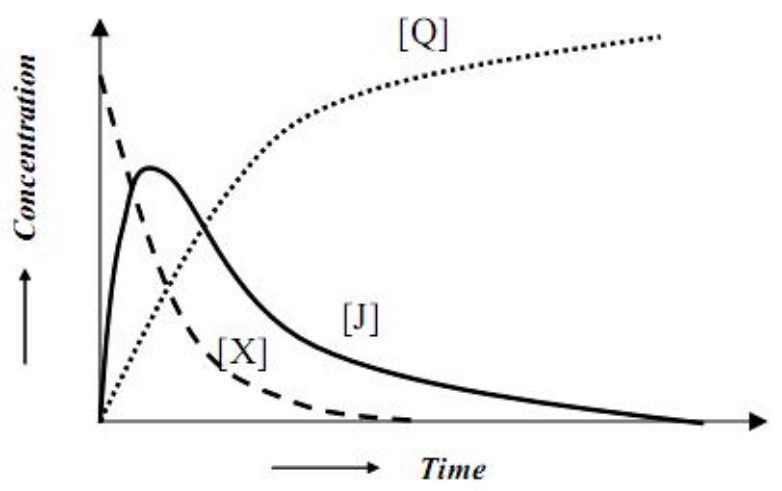

Four students are analysing this graph and trying to find out the mechanisms of the reaction. 
Ahmet says: "The reaction occurs in one step, and ' $\mathrm{J}$ ' is the activated complex. $\mathrm{X} \rightarrow \mathrm{Q}$ "

Erhan says: "No, the reaction occurs in two steps and the reaction mechanism is:

Step 1: $\mathrm{X} \rightarrow \mathrm{J}$ (slow)

Step 2: J $\rightarrow$ Q (fast), and the first step is the rate determining step"

Cem says: "Yes, I do agree with Erhan about the mechanism of the reaction, however the rate determining step is the second step"

Tarık says: "No, the reaction occurs in one step and ' $\mathrm{J}$ ' is a catalyst. $\mathrm{X} \longrightarrow \mathrm{Q}$ "

The students have some problems! Answer question (a) and (b) to help the boys to understand!

a) On how many steps do you think the reaction occurs? Please write down the possible reaction mechanisms and give reasons for your answer.

b) If you think the reaction occurs in more than one step, which step has highest rate and which step is rate determining step? Explain your answer as fully as you can.

\section{Enthalpy:}

Question 4. Consider these two reactions, occurring at the same temperature;

Reaction 1: $\mathrm{C}_{(\mathrm{g})}+\mathrm{P}_{(\mathrm{g})} \rightarrow \mathrm{B}_{(\mathrm{g})} \quad \Delta \mathrm{H}<0$ (Exothermic)

Reaction 2: $\mathrm{G}_{(\mathrm{g})}+\mathrm{V}_{(\mathrm{g})} \rightarrow \mathrm{Q}_{(\mathrm{g})} \Delta \mathrm{H}>0$ (Endothermic)

On the basis of this information some students are comparing the rates of these two reactions.

Serap says:"Reaction 1 is faster, because exothermic reactions occur faster than endothermic reactions."

Mine says: "The rates of these reactions are the same, because they occur at the same temperature"

Burcu disagrees: "No, it is not possible to compare the rates of these reactions, because there is not enough information given in the question"

The students are having some problems! Answer the question below to help the girls to understand!

What is your opinion about the rates of these two reactions? Please explain your answer as fully as you can. 
Question 5. Activation Energy: Consider these two reactions that have different activation energies (Ea) occuring at the same temperature:

Reaction 1: $\mathrm{Y}_{(\mathrm{aq})}+\mathrm{P}_{(\mathrm{aq})} \rightarrow \mathrm{C}_{(\mathrm{aq})} \mathrm{Ea}=92 \mathrm{~kJ}$

Reaction 2: $\mathrm{T}_{(\mathrm{aq})}+\mathrm{V}_{(\mathrm{aq})} \rightarrow \mathrm{Z}_{(\mathrm{aq})} \mathrm{Ea}=480 \mathrm{~kJ}$

Some students are discussing the meaning of activation energy and the relationship between activation energy and the rates of the reactions.

Zeynep says: "Activation energy is the kinetic energy of the reactant molecules. Thus the second reaction occurs faster than the first one"

Belma says:"No, activation energy is the total amount of energy released in a reaction. Thus there is not enough information for comparing the rates of these reactions"

The students are having some problems!

a) Explain in your own words what you understand by the term "activation energy".

b) Which reaction do you think is likely to be faster? Please explain your answer as fully as you can. 